\title{
BETWEEN TECHNOLOGICAL
} ADVANCEMENT AND PROTECTIONISM

\section{The Bumpy Evolution from MP3 Players to Smartphones in Korea}

\author{
Jimmyn Parc \\ Seoul National University and Sciences Po Paris \\ jimmynparc@gmail.com
}

\begin{abstract}
In recent years, K-pop or Korean popular songs have enjoyed immense popularity around the world. However, the situation was very different before the mid-2ooos when the industry was suffering from widespread piracy of its music. Furthermore, the emergence of the MP3 phone in the early 2000 s provoked two critical conflicts. One was between the producers of the MP3 phone who were large conglomerates and the manufacturers of the standalone MP3 player who were smaller companies that feared for their future. The other conflict was between the producers of the MP3 phone and the Korean music industry who believed this new device would hinder their development.

Given the current global popularity of K-pop, it is meaningful to analyze the position and rationale of these players at the time and their consequences. In brief, protecting existing industries hindered the corporate and industrial adaptions in the global competition and held back the momentum to explore innovation and a new business model. First, the MP3 player manufacturers encountered serious financial and managerial problems and even went into bankruptcy because they were too slow in pursuing change. Second, the Korean conglomerates were late in producing a new digital device, the smartphone, and entering its growing market. Third, the Korean music industry was able to survive but only because entertainment companies have adopted a new business model that generated alternative sources of earnings. This paper demonstrates the importance of having a broader view and recognition of industrial dynamics in formulating effective policies.
\end{abstract}

\section{Keywords}

digitization; hallyu; industrial protection; Korean music industry; k-pop; technological advancement 


\begin{abstract}
About the Author
Jimmyn Parc is a visiting lecturer at the Institut d'études politiques de Paris (Sciences Po), France and a research associate at the EU Centre, Graduate School of International Studies, Seoul National University in Korea. He is also a Research Associate of the European Centre for International Political Economy (ECIPE), Brussels, Belgium. He has published numerous academic articles and conducted a number of research projects related to the competitiveness of organizations, industries, and countries. For his main topic of research on the cultural and creative services industries, Dr. Parc uses historical and comparative approaches to understand further about their international business strategies. In particular, he focuses on the film and music industries which are faced with a changing business and trade environment as well as new challenges from digitization.
\end{abstract}


It is generally an accepted view that technological advancement has improved the quality of people's lives around the world. Yet this evolution has created conflict among several existing companies, industries, and their participants. It is often the case that these established companies or participants are resistant to innovation in the industries that they operate in. Their perception is that such change threatens their existing capabilities and products. In other words, these technological developments are considered as threats to well-established business models in which they have placed large personal and corporate investment (Kay).

A good example of this kind of resistance is the development of the French railway network in the early nineteenth century. Today, France is considered to be a country with a well-developed railway network. However, its development in the early nineteenth century was much slower than its neighbors, such as the United Kingdom and Germany (Dunham). While a significant factor was financing, there was also powerful opposition from the waterway and agricultural sectors. The waterway sector was concerned that the railway network would replace and take over its business. While for its part, the agricultural sector believed that the rapid and mass transportation of its products by rail would level the price structure between fertile areas and other parts of the country (Mitchell, "The Great Train Race" 30). Given these reasons, the farmers and waterway companies were largely against the construction of railways even though they would have brought benefits to the general public.

Such conflict is not just a story from the past but is still commonly found today. For example, since 2016, London's black cab drivers, one of the city's most iconic means of transportation, have been protesting against the services of the ride-sharing app Uber. The black cab drivers, who have acquired their license through a long and hard period of training, argued that Uber was endangering their livelihoods. More seriously, they claimed that Uber had broken laws and exploited its drivers as well as refused to take responsibility for the safety of their passengers (Farrell; Titcomb). Despite this criticism, some commentators have argued that Uber offers more competitive taxi fares and is also more accessible to customers (Holt).

Some may argue that this sort of conflict is only prevalent in Western societies, however, this is not the case. Many similar examples can be found around the world, including in East Asia. The industrial sectors that are involved vary from transportation to manufacturing, and even culture. The affected parties can be either large conglomerates or small and medium-sized enterprises (SMEs). However, when this issue involves cultural industries and/or the "alleged" victims are regarded as SMEs, social resistance against technological advancement becomes stronger and more widespread. This is because culture, as well as its related industries, is seen as part of a country's national identity and consists of characteristics that are 
regarded as needing protection and conservation. Furthermore, these industries have become more pronounced in recent years with the emergence of the political concept known as soft power. Since SMEs are seen as the weaker side when compared with the larger conglomerates, the public will generally put pressure on the government and policy-makers to provide favors to them. This tendency has become more intense since the financial crisis of 2008.

In this regard, the experience of the Korean music industry can contribute important lessons toward understanding this issue better. Since the late 1990s, Korean popular music or K-pop began to blossom and is now part of the globally popular phenomenon known as the Korean Wave or Hallyu. However, before it became firmly established in the mid-20oos, the situation was uncertain and complicated as the industry was suffering from increased levels of music piracy. Aside from pirated albums being widely available, accusations of plagiarism also became a big problem for the Korean music industry. These factors are seen as the main causes behind the underdevelopment of the Korean music industry as they dented its revenue (Parc, Messerlin, and Moon, "The Success" 141).

Given this context, the emergence of the MP3 phone, which combines functions of the MP3 player and the mobile phone, in the early 2000 stirred two critical conflicts in Korea. First, the MP3 phone was developed by Korean conglomerates known as chaebols and was considered as a replacement for the existing MP3 player which was mainly produced by local SMEs. As a result, the chaebols were perceived as seeking to drive out SMEs from the MP3 player market, who would then be considered as victims. Second, the Korean music industry believed that the rise of the MP3 phone would increase the levels of piracy and hinder their development by reducing revenues. ${ }^{1}$ As a result, both the $\mathrm{MP} 3$ player manufacturers and the music industry were against the introduction of $\mathrm{MP} 3$ phones in the market.

Given the current global popularity of K-pop, it would be a meaningful exercise to analyze carefully the industry's stance and the rationale behind its decisions at the time. With a clearer understanding of what actually happened and an analysis of its consequences, this paper provides important lessons on the rather complex relationship between technological advancement that is driven by digital devices on the one hand, and (cultural) industries and policies on the other. These lessons not only provide insight on the past and future of Korea's cultural industries but also interestingly shed some light for countries seeking to benchmark Korea. Lastly, it should be noted that this paper uses a number of secondary sources such as newspaper articles and reports because the conflict over the entrance of MP3 phones has not been studied much in academia, despite its importance and relevance. 
In order to address these complex issues, this paper is organized in the following way: The first section briefly explains the needs and importance of this study's approach. The second section introduces the comprehensive and systematic analytical tool that this paper utilizes. The third section scrutinizes, contrasts, and analyzes the difference in positions, decisions, and rationale behind the producers of the MP3 player and the MP3 phone (alongside the telecommunication operators), and the Korean music industry at that time as well as the consequences. The fourth section deals with a discussion that reflects upon the main points of the analysis. Lastly, the concluding section summarizes the main implications to be drawn from this study.

\section{THE IMPORTANCE OF AN APPROACH TOWARD TECHNOLOGICAL ADVANCEMENT: FROM MP3 PLAYER TO MP3 PHONE}

As K-pop began to emerge in the 1990 and gain international popularity, many argued that it was a fad and would not be sustainable in the future. Yet after two decades, the influence of K-pop has further expanded and diversified in terms of genres and geographical scope. Facing the sudden emergence of Hallyu across the world, a number of existing studies have attempted to analyze the core reasons behind its success by assessing, (1) cultural aspects such as cultural proximity, diversity, and transnationality (Oh, "The Globalization of K-pop"; Jin, "New Korean Wave"; Jin and Ryoo; Jung and Shim); (2) institutional aspects such as government support and private corporate efforts (Choi; Lee, "Managing the Transnational"; Jin, "The Power of the National-State"); (3) industrial aspects like production and business activities (Parc and Kawashima; Parc, Messerlin, and Moon); and (4) consumption aspects such as fandom and the Internet (Choe and Russell; Jin, "New Korean Wave"; Jung, "Fan Activism"; Leung; Oh and Park).

Among them, Sang-Hun Choe and Mark Russell's Bringing K-pop to the West: Social Media Helps South Korean Bands Find New Fans and Dal Yong Jin's New Korean Wave: Transnational Cultural Power in the Age of Social Media have highlighted that K-pop has become internationally popular through dissemination on social network services (SNS) and Korea's advanced information communication technology (ICT) based on well-developed internet connections and smartphones. The case of the Korean music group BTS or Bangtan Boys, who debuted in June 2013, has strongly supported this aspect and was clearly evident when they won the 2017 and 2018 Billboard Awards for Top Social Artist beating Justin Bieber, Selena Gomez, and other well-known American pop artists. 
Before the active use of SNS and the Internet, the Korean music industry was focused on physical albums like many other music markets around the world. However, over the last decade, the Korean music industry and its related companies have incorporated SNS and the Internet more actively than their counterparts in other countries (Parc and Kawashima). Among many of the existing studies, Parc and Kawashima's "Wrestling with or Embracing Digitization in the Music Industry: The Contrasting Business Strategies of J-pop and K-pop" clearly demonstrates how the Korean business sector has embraced digitization much earlier and more actively than the Japanese music industry. This is notable because J-pop was internationally more popular before the emergence of K-pop.

Existing studies have provided various information and analyses from the perspective of the music industry, and some have shown how the Korean music industry's embrace of the Internet and SNS was facilitated by the rise in the use of digital devices such as computers, MP3 players, smartphones, and tablet PCs. As yet though, few studies have focused on the technological perspective in understanding the development of the music industry. Therefore, an in-depth analysis of the technological advancement that helped the Korean music industry needs to be rigorously studied in order to understand the emergence of K-pop from a broader perspective. In this regard, it is important to note that Korea began to shift toward an IT-dominated economy during the 1997 economic crisis - at least ten years before other developed countries. Therefore, digital devices also appeared relatively early in the domestic market.

Although their dominance only lasted for a short period of time, $\mathrm{MP} 3$ players and MP3 phones played a critical role in the evolution of the music market, a fact which provides us with important policy implications. Understanding the very rich history of technological advancements-in particular, its non-linear trajectory and its trial-and-error approach-and their crucial consequences will help toward forecasting how similar events will emerge in the future.

\section{METHODOLOGY: A DYNAMIC FRAMEWORK FOR THE MUSIC INDUSTRY²}

As this paper deals with an ex post analysis to examine the stance and rationale behind the three industrial participants, a comprehensive and systematic analytical tool is required. In particular, since the technological advancement for the Korean music industry emerged with digitization, the tool should incorporate digitization within its framework. In this regard, a useful study is Parc and Kawashima's dynamic framework for the music industry. Based on a critical review of existing studies, their approach incorporates both the emergence of the Internet, which 
occurred from the late 1990 os through to the early 200os, and the "routinization" of the Internet, which happened after the early 2000 .

Central to Parc and Kawashima's analysis is the incorporation of the diamond model which is based on Porter's Diamond Model and its extension. This approach is regarded as one of the most comprehensive among various other similar models (Moon, Rugman, and Verbeke). Moon, Rugman, and Verbeke expanded the Diamond Model to the Generalized Double Diamond (GDD) Model whereby multinational activity is formally integrated into the original model. For its approach, Parc and Kawashima's framework has four factors that change their practice when facing digitization: technology, producers, consumers, and business context. Each factor has two sub-factors in terms of sophistication; technology has hardware and software, producers have basic and advanced, consumers have size and quality, and business context has structure and rivalry (see Table 1).

Table 1. A Dynamic framework for the music industry

\begin{tabular}{l|l|l} 
Factors & Sub-factors & Practice changes \\
\hline \multirow{2}{*}{ Technology } & Hardware (A-1) & Analog $\Rightarrow$ Digital \\
\cline { 2 - 3 } & Software (B-1) & Possessing $\Rightarrow$ Accessing \\
\hline \multirow{2}{*}{ Producers } & Basic (A-2) & Offline $\Rightarrow$ Online \\
\cline { 2 - 3 } & Advanced (B-2) & Complexity $\Rightarrow$ Simplicity (of production) \\
\hline \multirow{2}{*}{ Consumers } & Size (A-3) & Album (bundle of songs) $\Rightarrow$ Song (a piece of music) \\
\cline { 2 - 3 } & Quality (B-3) & Audio $\Rightarrow$ Visual \\
\hline \multirow{2}{*}{$\begin{array}{l}\text { Business } \\
\text { context }\end{array}$} & Structure (A-4) & Specialization $\Rightarrow$ Integration \\
\cline { 2 - 3 } & Rivalry (B-4) & Threat $\Rightarrow$ Opportunity \\
\hline
\end{tabular}

Source: Parc and Kawashima.

Entering the era of digitization, diffusion, and consumption has changed with hardware advancement (A-1). Under these conditions, less sophisticated copyright practices of music producers will help with the wider and easier diffusion of music. In addition, consumers have shifted their preferences from possessing music to accessing streaming service providers (IFPI; IPSOS and IFPI) (B-1). Therefore, many entertainment companies, such as SM Entertainment, YG Entertainment, JYP Entertainment, and Big Hit Entertainment, have actively used online services or found other effective ways to diffuse their content through the Internet. 
Digitization and the Internet also provide opportunities for companies to expand the market easily from a domestic to an international scope. Hence, producing music that is appealing to both sets of fans is crucial if they wish to enhance their business performance (A-2). Furthermore, the distance between producers and their consumers has shortened, and the structure of the industry has simplified. This trend induces for more start-ups than before. Consequently, the music industry has become more dynamic and diversified (B-2).

The way in which consumers enjoy music has changed; from purchasing a complete album to accessing only a few favored songs (A-3). Furthermore, as consumers use digital devices such as smartphones and tablet PCs to enjoy music, the visual image of singers or band groups has become as important as the audio aspect of the music (Messerlin and Shin 421-422). As such, consumers appreciate the value of "music to listen and watch" more than that of "music to listen" (B-3). Digitization has also accelerated the turnover of the music industry with increased demand and rapidly emerging trends. In order to meet these changes, the industry needs to integrate various functions for effectiveness and efficiency, rather than focusing on specialization (A-4). All of these changes coupled with increased globalization has created more competition in a different setting that stands in contrast to the situation before. Hence, this has generated new opportunities (B-4).

According to Parc and Kawashima, "Series A" sub-factors and their practices happen during the emergence of the Internet whereas the counterparts of "Series B" are found during the routinization of the Internet. However, all these developments have occurred pretty much simultaneously and within a relatively short period of time. It is important to note that this kind of practice changes is happening all over the world when facing the global trend of digitization. Due to technological advancements and the rapid adaptation to digitization among industry participants, these dynamics happened earlier and are more noticeable in Korea than in other parts of the world (Parc and Kawashima). This shows that analyzing the Korean music industry can provide meaningful implications for other countries. The course of events for each entity in Korea as described in the dynamic framework (Table 1) is presented along with a brief summary at the end of each section.

\section{COURSE OF EVENTS WITH DIFFERENT APPROACHES: FROM MP3 PHONE TO SMARTPHONE}

In the 1990s, the Korean music industry began to emerge. Consequently, the sales of albums, in the form of cassette tapes and CDs, increased significantly. However, the introduction of $\mathrm{MP}_{3}$ players from 2001 began to replace cassette tapes and 
CD players, which slowed down the sales of albums. Soon, MP3 players were in competition with a new digital device, the MP3 phone. From the beginning, the manufacturers of $\mathrm{MP} 3$ players were against the chaebols producing MP3 phones. Alongside them, the Korean music industry was also against the telecommunication operators selling and servicing these new devices. The difference in the position of the two sides brought about a conflict that lasted for several years. This section scrutinizes and compares the contrasting stances among the producers of $\mathrm{MP}_{3}$ players and $\mathrm{MP} 3$ phones, as well as the Korean music industry.

\section{Producers of $M P_{3}$ Players}

The world's first commercialized or mass-produced MP3 player was developed by a Korean company, Saehan Information System in 1998 (Van Buskirk). In contrast to the United States where MP3 players were based on a hard disk drive (HDD), such as Apple's iPod in 2001, Korean companies used the more effective flash memory. It would take a few more years until Apple would release its first flash memory-based $\mathrm{MP}_{3}$ player known as the iPod nano (see Figure 1). Thus, the Korean SMEs who produced most of the world's MP3 players were able to enjoy dominance in the global music market until the appearance of the iPod nano in 2005 .

In the late 1990s, a popular trend prevailed in Korea where consumers exchanged MP3s through an online network system and kept these files on the hard drive of their PC. In this environment, the key requirements for MP3 players were (1) to hold as many files as possible on a small device, (2) to produce a high quality sound through earphones, and (3) to be mobile. At the same time, most producers of $\mathrm{MP} 3$ players were SMEs and the market size was at first relatively small (for further information, please see the next section "Producers of MP3 Phones"). Given the capabilities of MP3 players, the Korean music industry was worried about the increase in copyright violations that might be caused by the prevalence of such devices. However, the main target for the music industry over copyright infringement was not the $\mathrm{MP} 3$ producers but the $\mathrm{MP} 3$ music providers such as Soribada, a peer-to-peer sharing service, and Bugs, a music streaming service provider (Yang; Yoo, "Ŭmbanŏpgye").

By 2003, iriver, a consumer electronics SME, accounted for 52 percent of the Korean market while other companies such as Cowon and Bluetek took up 13 percent each (Yoo, "MP3 pŭleiŏ"). ${ }^{3}$ By this time, the MP3 player market in both Korea and abroad had surprisingly expanded; companies such as Creative Labs and Dell as well as a few other Chinese companies began to enter the business (Yoo, 


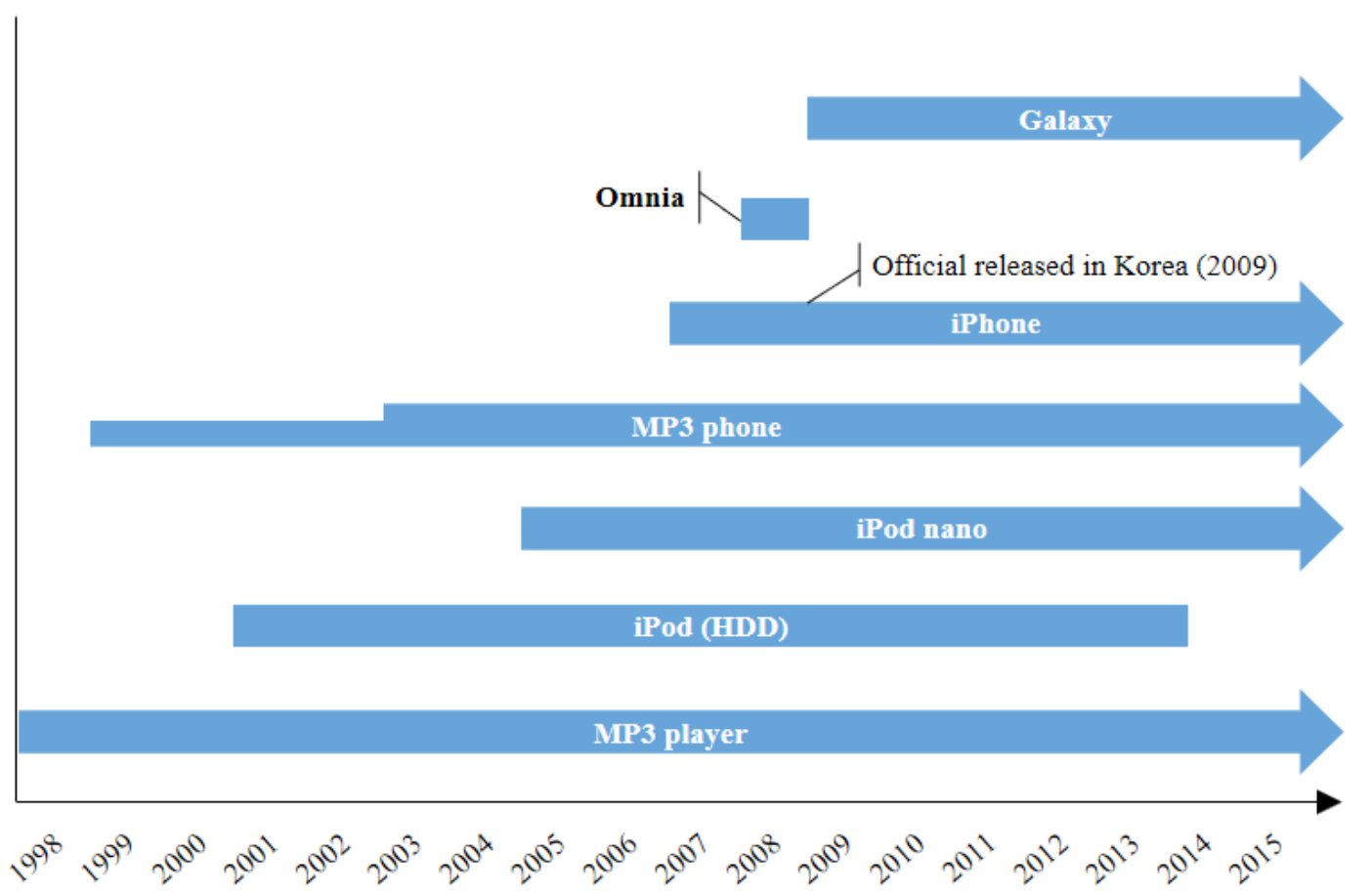

Fig. 1. Timeline of digital devices

Notes: (1) arrows mean continuity of production; (2) MP3 phone firstly appeared in 1999, but it only became visibly prevalent in the market from early 2003; (3) the iPhone was internationally released in 2007, but was not released until 2009 in Korea.

"MP3 pŭleiǒ"). Despite this new competition, a few Korean SMEs who dominated the Korean market also proceeded to engage in a number of foreign markets as major shareholders. An example of such confidence was the decision by iriver to enter the American market through aggressive marketing. This included the HDDbased MP3 player which was a sector dominated by Apple (Yoo, "MP3 pŭleiŏ") (see Figure 2). 


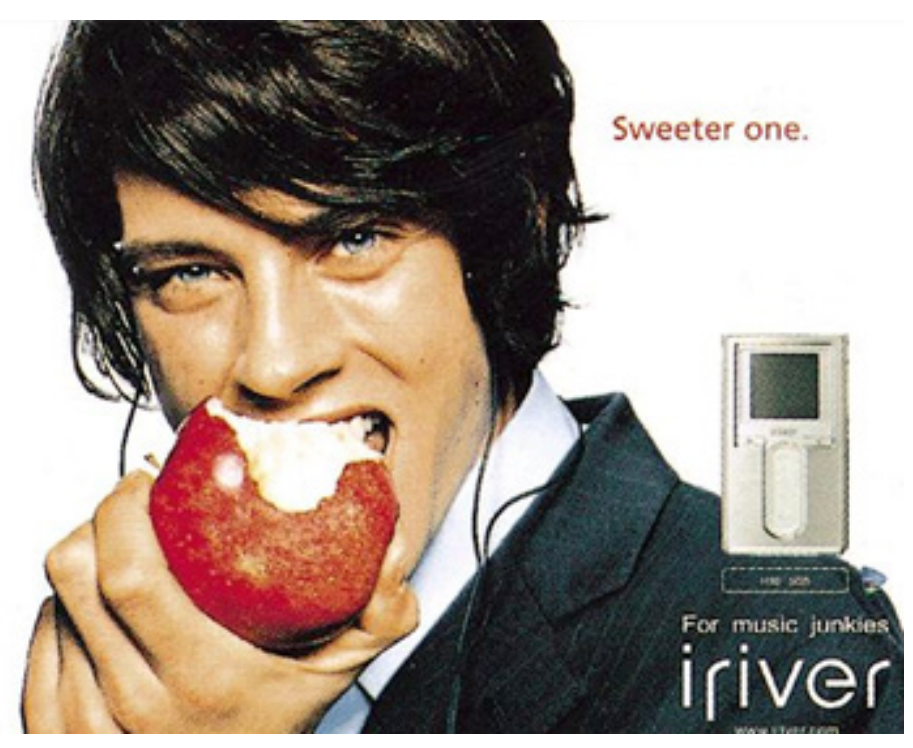

Figure 2. An example of iriver's aggressive marketing

Source: Dorozhin Alexey.

In Korea, Samsung Electronics (hereafter Samsung) sought to actively target the MP3 player market by lowering the price for its products in 2004 (Lee, "Samsonng.LG"). Internationally, Apple finally released the iPod nano in 2005 after acquiring a massive quantity of flash memory chips from Samsung and Toshiba at a good price. At this stage, the MP3 player market became more competitive domestically and internationally. In particular, Samsung and LG Electronics (hereafter LG) developed MP3 phones in 1999 and 2000 respectively, then released them again in 2003 by utilizing aggressive tactics as the MP3 player market expanded (see Figure 1). Apple also began to develop its iPhone in secret from 2004 (Rowinski). Although it was not made public, there was a general expectation in the electronics industry that Apple would produce a digital device that would combine the iPod with a mobile phone. At the same time, Apple's iTunes was transformed from a simple music player to a multi-media content manager.

Facing the emergence of MP3 phones and with rumors of the iPhone circulating, the SMEs that produced MP3 players were slow to react particularly as they had support from the Korean media and several government organizations. Instead of responding, they expressed a rather complacent attitude of superiority by arguing that they had accumulated more know-how from the global market and that MP3 players offered larger memory capacity as well as better sound quality. Specifically, 
they predicted that, given the technology of the time, devices with multi-functions would have a limited battery life compared to standalone MP3 players (Shin). In effect, these SMEs focused on producing sophisticated MP3 players with improved sound quality, newly added functions, futuristic designs, and increased storage capacity. As a result, the price of $\mathrm{MP} 3$ players increased. For example, one MP3 player at the time which only had one-gigabyte of storage memory retailed for US\$ 500 whereas the two-gigabyte iPod nano cost only US\$ 199.

By utilizing Parc and Kawashima's dynamic framework, an interesting evaluation can be drawn. While the producers of MP3 players used new technology from the beginning during the era of digitization (A-1), these companies overlooked the importance of software development by focusing too much on hardware and its functions (B-1). When music files appeared online and they were widely available through free downloads, the MP3 player was an ideal device to store files, especially as it was small and portable (A-2). However, music producers in the late $2000 \mathrm{~s}$ would begin to release their content as music videos directly through SNS and the Internet in order to simplify their business (B-2). At this stage, the MP3 players lost their role in the simplified chain from production to consumption of music.

MP3 players were suitable when consumers collected songs that they enjoyed instead of purchasing a complete album (A-3). However, since the late-20oos, the visual appeal of music videos has become as important as the audio sound (B-3). MP3 players were no longer the suitable device for this change. Along with this, since the mid-2ooos there was a trend among telecommunication operators to integrate their business with recording companies in order to facilitate better procurement of sound sources; SK Telecom Co. (SKT) merged YBM Seoul Records and KT Freetel Co. (KTF, currently KT Corp.) merged Bluecord (A-4). Facing the introduction of MP3 phones and smartphones, the SMEs who produced MP 3 players decided to compete directly with the large global conglomerates that produced more competitive devices. That $\mathrm{MP}_{3}$ players became a simple everyday item and new digital devices were released notwithstanding, these SMEs decided to include more complicated yet unnecessary functions in their players which increased the product price instead of simplifying functions of their products. In this way, they did not take the emergence of MP3 phones as an opportunity to develop new products (or business) for their future prosperity (B-4). In the end, many of them went into bankruptcy or were merged with the conglomerates. 


\section{Producers of MP3 Phones (and Telecommunication Operators)}

Samsung developed its own MP3 player in 1998 and released the first one in 1999; this was three years before Apple released the iPod in late 2001 (Song). In the same year as the iPod release, Samsung unveiled the world's first MP3 phone, the $\mathrm{SCH}$-A1oo (Samsung). However, at the time the MP3 player market in Korea was considered to be too small for these large conglomerates. Compounding this, there was also a rumor that Samsung lost its interest in the $\mathrm{MP} 3$ player business (Jung, "Wŏlyopokŏsŭ"). In the end, the company handed this MP3 player sector over to one of its Chinese subsidiaries, Bluetek (Kim, "Samsŏngchŏncha MP3saŏp").

From 2002 to 2003, the MP3 player market doubled in size (Yoo, "MP3 pŭleiŏ"). As it increased significantly and was expected to grow further, Samsung immediately re-entered the MP3 player market. As MP3 players appeared, the sales of physical album decreased (Chichŏk chaesankwon). Additionally, in early 2004, LG and Samsung re-released their MP3 phones (LP-30oo and SPH-V4, respectively) in the market (Kim, "LG, MP3pŏn"; Kim, "Samsŏngchŏncha 'blutek"). At the same time, the telecommunication operators developed their own music streaming services which allowed their customers to download music freely: MelOn by SKT in 2004 and Dosirak by KTF in 2005. As mentioned before, these operators also merged several existing recording labels into their business.

Under these circumstances, many in the Korean music industry were against the chaebols selling MP3 phones. They feared that the expected impact of this new device would have a more negative effect on the music industry than with the emergence of MP3 players. Even several well-known singers, such as Hyori Lee, held solo demonstrations against the producers of MP3 phones. Reinforcing such concerns, the Korean music industry argued that there should be no free music content for $\mathrm{MP} 3$ players and $\mathrm{MP} 3$ phones. Furthermore, they advocated for digital rights management (DRM) - a technology that ensures $\mathrm{MP}_{3}$ files are only available for a few days - to be applied to all downloaded music for MP3 phones in order to restrict the use of copyrighted works. On top of all these measures, they also wanted to ensure that the sound quality of downloaded music would not be as good as that of the physical copy. However, consumers were against these restrictions and, in the end, many found a way to disable DRM for their convenience (For further information, please refer to Chichŏk chaesankwon).

Facing such unexpectedly strong opposition, the telecommunication operators and the chaebols hesitated in their promotion of MP3 phones. The only exception was LG Telecom Co. (LGT, currently LG Uplus Corp.), which invoked the other operators to closely monitor LGT's stance. While the music industry was against

MP3 phones, Korean consumers favored these devices and argued that their rights 
should also be protected in order for them to enjoy music (Oh, "Iyongcha ŭi"). In this situation, a settlement for the MP3 phone conflict was prolonged because of LGT's lone approach. Part of the reasoning behind their strategy was that, among the major three telecommunication operators in Korea, they had the smallest market share yet were still a subsidiary of the conglomerate LG that produced MP3 phones. Therefore, it is believed that LGT tried to take advantage of this opportunity to catch up with its competitors by selling its parent company's MP3 phones. The fact that LGT quickly increased its sales profits after it began to sell MP3 phones supports this view (Chichŏk chaesankwon).

In order to resolve this conflict and seek an agreement with LGT, several interest groups such as the Recording Industry Association of Korea (RIAK), the Korean Association of Phonogram Producers (KAPP), and the Korea Entertainment Producer's Association (KEPA) formed the Council for the Urgent Measures on Korean Popular Music. In November 2004, all sides finally reached a compromise. It was agreed that from July 2005, music streaming services and MP3 downloads from the service providers would be charged. At the same time, a fund of KRW10 billion (approximately US\$ 9 million) would be raised to improve consumer awareness on copyrights and its related regulations (Kim, "LGT.5 gae"). Despite these developments, the MP3 phone still managed to acquire a large share of the $\mathrm{MP} 3$ player market by 2007, but it was quickly replaced by smartphones starting from 2009 when Apple released the iPhone in Korea.

These MP3 phone producers fully integrated the current hardware technology to their digital devices (A-1). After witnessing the emergence of music streaming service providers, $\mathrm{MP} 3$ producers knew the importance of accessing music (B-1), but failed to combine software technology to that of the hardware in which they had their main competitiveness. When producers released their music online as $\mathrm{MP}_{3}$ files, the MP3 phone was a suitable device as well as the MP3 player (A-2). However, when music producers simplified their production-distribution channel and released music directly online through the Internet and SNS, the MP3 phone lost its main utility as did the MP3 player (B-2).

From the consumer perspective, the $\mathrm{MP} 3$ phone was better than the $\mathrm{MP} 3$ player on a functional level, only one device instead of two (A-3); however, once the visual image became as important as the audio sound, the MP3 phone was no longer the ideal device (B-3). While Apple began to develop its iPhone (Rowinski) and iTunes evolved into a more integrated platform that included a media player, a library database, internet radio broadcaster, music and application purchases, the MP3 phone producers failed to adopt many of these new features (A-4). In particular, when Apple released its first iPhone in 2007, Korea was not included in the initial release phase due to regulatory issues. It was only in 2009 that the iPhone was finally 
released in Korea (see Figure 1). Various sources claim that Korea's MP3 phone producers and telecommunication operators considered the iPhone's release as a threat and it is believed that they sought to obstruct Apple's market penetration (B-4). In this regard, it is noteworthy that Samsung only began to produce its own comparable smartphone, the Galaxy, after 2009..$^{5}$

\section{The Korean Music Industry}

Shortly after the liberation of Korea from Japan in 1945, the Korean music industry began to develop. As the United States military was stationed in Korea, American music had a significant influence on Korean music. Throughout the $1950 \mathrm{O}$ and 1970s, the younger generation of musicians enjoyed Western music and began to adopt it in their own sound (Parc, Messerlin, and Moon). However, the Korean music industry did not gain enough earnings from selling albums. Rather, during this period, most musicians made their money by performing at clubs located in the US Army bases in Korea and later in private clubs. For example, it is assumed that there were 264 clubs in the US military bases across South Korea and the Korean music industry gained approximately US\$ 1.2 million per annum during the 1950 from these performances (Lee, "Migunkŭlŏpsŏ"). ${ }^{6}$

From the 1960 s to the 198 os, the Korean music market was still underdeveloped. It is often said that the music industry was negatively impacted by piracy throughout this time. However, the ones who produced the pirated albums were actually Korean record labels (Kim, "A Study on the Process"). This contradiction was actually a way to overcome their financial difficulties. Simply, in the underdeveloped music market of the 1960s-1980s, selling pirated albums was more profitable than selling the originals (Parc, Messerlin, and Moon). This fact can be interpreted as either the price of a regular album was higher than the actual purchasing power of Korean consumers at that time or that the demography of music consumers had changed from the older generation to the younger one which was comprised of people who were more limited in their economic activity.

In the mid-1980s, singers such as Moon-Se Lee and Jin-Sub Byun helped change the trend of Korean music from trot, the older form of Korean pop music, to ballad. By the mid-1990s, the Korean music industry began to further boom with Seo Taeji

and Boys and Gun-Mo Kim who introduced different genres of Western music such as rap, hip-hop, and reggae. All of these changes contributed toward increasing the size of the music market by attracting more of the younger generation. As beepers and mobile phones began to appear, the Korean telecommunication operators soon utilized these popular songs as a sound source for ringtones. With the prevalence 
of mobile phones in the 20oos, the ringtone market expanded further and has become the most stable source of earnings for the Korean music industry (Cha).

With the introduction of MP3 players, the Korean music industry was on another step toward change. This new digital device had a significant impact on the sales of physical albums. Yet instead of responding directly to MP3 player manufacturers, the Korean music industry went after the $\mathrm{MP}_{3}$ music providers such as Soribada and Bugs and accused them of copyright infringement (Yang; Yoo, "Ǔmbanŏpgye"). Nonetheless, it overlooked that Korean consumers were very much more accustomed to downloading music for free. All of this made it a difficult challenge for the Korean music industry to strictly control online piracy. Thus, these responsive actions were not effective enough to protect the industry. Soon, the MP3 phone was produced and began to be widely sold. With this new technology in the market, the recording labels were then slowly merged with the telecommunication operators.

Because the most stable earnings for the music industry were mainly gained from the sales of ringtones through the telecommunication operators, the Korean music industry did not oppose directly the merger and acquisition between them and the recording labels. Rather they were against the manufacturers of the $\mathrm{MP}_{3}$ phone. In particular, the industry was against LGT because (1) this operator was a subsidiary of LG that produced MP3 phones and thus expected to bring about a greater impact, (2) LGT had the smallest market share, hence received the smallest earnings compared with the other operators which would result in minimum risk, and (3) beating LGT would be advantageous for future negotiations with the operators as well as the producers of the MP3 phone. As mentioned before, a compromise was eventually reached in November 2004 that sought to resolve the conflict over the MP3 phone. However, it was not enough to "protect" the music industry in the coming years because the way of consuming music shifted from MP3 players to smartphones and tablet PCs in terms of devices, and from a few domestic service providers to international providers such as Facebook, YouTube, and other online platforms.

Once the Korean music industry had retained a stable source of earnings from the operators, it did not want to abandon the market easily although the trend changed from analog to digital (A-1). Having stuck to the traditional market, the Korean music industry responded slowly to changes in the way in which music was consumed, specifically from possessing albums to accessing streaming platforms (B-1). Furthermore, the Korean music industry neglected several other new trends. First, music producers and entertainment companies preferred to release their music online (A-2). Second, they have simplified their business structure by 
embracing alternative sources for earnings; these have generated more profits than what was previously gained from copyrighted works (B-2).

While consumers prefer to enjoy music through their MP3 phone, the Korean music industry was not on the consumers' side but was rather the advocate for a few organizations concerned with copyright enforcement (A-3). The Korean music industry's strong resistance against the music service providers and the $\mathrm{MP} 3$ phone led consumers to shift from audio to visual through the use of other devices that provide images, such as smartphones and tablet PCs (B-3). Korean entertainment companies have become less sensitive about copyrights because they are not the direct beneficiaries in receiving royalties. Instead, they have created other more beneficial sources for earnings, such as concerts, fashion, and restaurant businesses (A-4). The center of the music industry has thus moved from the operators to the entertainment companies. If the Korean music industry was genuinely interested in supporting the earnings for song writers and singers, the domestic market should have been opened up earlier to foreign service providers such as iTunes who pay more royalties. Such an effort would have also offset the impact from the operators and producers of $\mathrm{MP} 3$ phones by holding each other in check (B-4). Above all, it would have then formed a more balanced and dynamic environment that would have contributed toward the further diffusion of K-pop.

\section{DISCUSSION}

In the era of digitization, a number of content producers have complained about the new environment and service providers that behave differently from other traditional players. For example, a Korean singer, Yong Lee, announced that his new album was a hit and that eight thousand copies were sold. In actual fact, this album resulted in a loss of KRW16o million (approximately US\$ 141,00o) when all the fees are taken into account. This includes recording costs, album cover design, music production, writing, and public promotion, which amounted in total to about KRW 200 million (approximately US\$177,000). Thus, he earned only KRW 40 million (approximately US\$ 35,00o) from album sales (Lee, "Chŏchakkwoncha"). However, if he were able to diffuse his music internationally and had held concerts after increasing his popularity around the world, he would have earned much more than he actually did. The survivors are those who have adjusted themselves to a change in their environment. 
We also should not overlook the importance of globalization. In contrast to the past, suppliers and consumers can always find their counterparts through globalization. As hinted before, the strong resistance of the Korean music industry led domestic consumers, at best, to use international service providers such as Amazon Music, Facebook, Spotify, and YouTube, or illegal downloads at worst. In other words, the Korean music industry's resistance paradoxically promoted international platforms or increased piracy in Korea. But more importantly, one of the critical reasons why K-pop has gained its international popularity is the wide availability of its content online which would not be possible if there was a strict copyright practice. The Korean entertainment companies have not stuck to copyrights, but have instead sought to find newer business models that are proculture and pro-business at the same time.

Regarding business practice, Korean media outlets have recently reported that the local price for "allegedly" the same products produced by the chaebols is more expensive than the international one. In order to mock it, a new term hogaeng, or "stupid customer," has appeared. However, one should note that the same Korean media outlets have criticized the chaebols for setting a low price for their MP3 players compared to the SMEs in both domestic and overseas markets. Why is it that when SMEs set a high price for their products it is considered good, whereas when the chaebols do a similar action it is considered more negatively? Why has such a double standard been applied? Because of the different corporate size? Should not the consumer be more important than any other player when it comes to the price? The history of the evolution from MP3 players to smartphones has much merit in this regard that requires further study.

\section{CONCLUSION}

Facing technological advancement, having holdbacks within industries and society is a common response. The history of the transition from $\mathrm{MP}_{3}$ players to smartphones in Korea shows interesting stances among each of the industry participants: specifically, it was the producers of MP3 players and the Korean music industry who were both against the producers of $\mathrm{MP} 3$ phones. Regarding the conflict over MP3 phones, the media outlets in Korea favored the manufacturers of MP3 players since most of them were SMEs. As a result, the chaebols were initially hesitant to enter the market with their new devices including the MP3 phone. All of these reactions led the producers of $\mathrm{MP} 3$ players to respond too late and too slowly to changes in the business environment. Eventually, many of them encountered financial difficulties and/or eventually entered into bankruptcy. 
The conflict between the producers of $\mathrm{MP}_{3}$ phones and the Korean music industry was more severe. By sticking too much to the old conventional business model and seeking to preserve their source of earnings, the Korean music industry opposed the release of $\mathrm{MP} 3$ phones in the market. The industry did not interpret correctly the preferences of consumers rather they were only interested in their own gains. However, as consumers changed their way of enjoying music, shifting from audio to visual, the industry was unable to achieve what it sought. The conflict itself has been further complicated but is now less influential due to a new business environment. While the conflict provoked great transaction costs, the producers of MP3 phones were also late to develop a more innovative digital device, specifically smartphones. Later, the producers had to invest much effort in order to catch up with their competitors in the smartphone industry; LG has not been visible in the market.

While these three entities were in turmoil, a new hegemonic power, the entertainment companies, emerged as a new player in the music industry. Because they are not reliant upon the old copyrights regime, they have found a new business model by adjusting themselves to changes in their environment. They have released their music online with very few restrictions, which ensures that fans in different parts of the world have easy access to K-pop songs. Along with regular feedback from these fans, the Korean entertainment companies are able to learn about preferences and tastes of fans, which helps them to produce more appealing content. Through this virtuous circle, K-pop has been very successful and has been able to expand its popularity across the world.

Unfortunately, old trends continue to survive and may put Hallyu's content in danger. Several international organizations such as the French Society of Authors, Composers and Publishers of Music (SACEM) seek to persuade the Korea Music Copyright Association (KOMCA) to strengthen their copyrights regime and system of levies. The Korea Copyright Commission (KCC) has also recently begun to monitor copyright violations in many countries, notably in Southeast Asia. However, one should consider that the French music industry in recent years has not produced much internationally popular content despite observing stricter copyright practice. It is important that Korean organizations clearly understand the critical reasons for the international popularity of Hallyu's content: globalized content, business-oriented model, wide diffusion and availability, and business activities that are less attached to copyrights.

It is often the case that the development of society, culture, and industry is held back by a few ego-centric organizations where vested interests are so powerful that 
progressive innovation can be staved off forever. Development is like going upstairs; without having the most up-to-date technology, we cannot go up and forward. If society, culture, and industry really want to achieve further development, we should not miss what Isaac Newton once said, "if I have seen further it is by standing on the shoulders of giants." He was insightful enough to use "standing" not "trampling" and this aspect should be clearly understood and kept in the back of our minds. 


\section{Acknowledgment}

This work was supported by the Laboratory Program for Korean Studies through the Ministry of Education of the Republic of Korea and the Korean Studies Promotion Service of the Academy of Korean Studies (AKS-2015-LAB-2250003). 


\section{Notes}

1. In this article, "the Korean music industry" has two usages; one is to refer to the industry as a general term and the other is to refer to an alliance of interest groups such as the Recording Industry Association of Korea (RIAK), the Korean Association of Phonogram Producers (KAPP), and the Korea Entertainment Producer's Association (KEPA) who all have long advocated copyrights (see "2. Producers of MP3 Phones [with Telecommunication Operators]" section). In order to draw a critical implication in the "Discussion" section, the two usages were employed without much distinction.

2. This part heavily relies on Parc and Kawashima.

3. Bluetek, a Chinese subsidiary of Samsung, produced MP3 players which were sold under the brand name of Samsung.

4. Before April 2009, Korean law did not allow mobile phones to have a Wi-Fi function. This was intended to protect domestic telecommunication operators and content providers. Sang-Hoon Kim argued that this law helped the operators to gain more profits and that they were not willing to sell the iPhone that they believed would negatively affect this setup. In 2010, Jong-Wha Kim and JungHwan Lee reported a rumor that Samsung asked SKT, the number one operator in Korea, to delay selling the iPhone in order to protect the domestic smartphone market, notably for Samsung. Yuni Jung reported that Seok-Chae Lee, a former chairman of KTF confessed that two chaebols asked KTF not to sell the iPhone. According to Yuni Jung, Seok-Chae Lee also stated that due to the Wi-Fi function in smartphones, data consumption increased 153 times during 2009-2012 which reduced profits significantly.

5. In fact, Samsung released its first smartphone, Samsung Omnia in 2008 while Apple released its first iPhone in 2007 (see Figure 1). However, the Omnia was not comparable with the iPhone and suffered in both the domestic and international markets. Samsung was able to emerge as a global smartphone producer after 2009 with its smartphone brand Galaxy.

6. During the 1950s, the total annual export of South Korea reached US\$20.0 million (Ministry of Trade, Industry and Energy). Hence, the income of US\$ 1.2 million that the Korean music industry gained from the US military bases was quite significant. It should be highlighted that this amount was gained from performances, not from sales of albums, which interestingly is very similar to how the Korean entertainment companies of today operate. 


\section{Works Cited}

Cha, woojin. "Han'guk ŭmak sanŏp kwa K-pop ŭi pyŏnhwa [The Korean Music Industry and Changes in K-pop]." Munhwa Kwankwang Insight, vol. 115, 2018, pp. 2-4.

Chichŏk chaesankwon, editor. "Ǔmwonchechakchahyŏpheo wa LG Telecom gan ŭi MP3 pon punchaeng [The Conflict over the MP3 Phone between Korean Association of Phonogram Producers and LG Telecom]." Chichŏk chaesankwon, vol. 2, 2004, pp. 206-219.

Choe, Sang-Hun, and Russell, Mark. "Bringing K-pop to the West." The New York Times, 5 Mar. 2012, p. B10.

Choi, Young-Hwa. "IImyŏngbak chŏngbu ŭi kiŏpgukka pŭrochektŭ rosŏ hallyuchŏngchack: Chŏllyakgwangye chok chŏpgŭnbŏp ŭl tonghan kucho wa chŏllyak punsǒk [The Korean Wave Policy as a Corporate-State Project of Lee Government: The Analysis of Structures and Strategies Based on the Strategic-relational Approach]" Economy and Society, vol. 97, 2013, pp. 252-285.

Dorozhin, Alexey. “История Компании iRiver. Часть 2 [History of iriver, Part 2].” Mobile.Review, 28 Nov. 2006, http://mobile-review.com/mp3/articles/iriver-history-2. shtml. Accessed 19 Apr. 2018.

Dunham, Arthur. "How the First French Railways Were Planned." Journal of Economic History, vol. 1, no. 1, 1941, pp. 12-25.

Farrell, Jeff. “Uber Ban in London: Black Cab Bosses Hail TFL Decision as 'Right Call.' The Independent, 22 Sept. 2017, https://www.independent.co.uk/news/uk/home-news/tfltransport-for-london-ban-uber-london-sadiq-khan-black-cab-a7961176.html. Accessed 3 May 2018.

Holt, Richard. "Black Cabs Must Face up to Reality - It's All Uber Now." The Telegraph, 19 Sept. 2016, https://www.telegraph.co.uk/news/2016/o9/19/black-cabs-must-face-up-toreality--its-all-uber-now/. Accessed 27 Apr. 2018.

IFPI (International Federation of the Phonographic Industry). IFPI Digital Music Report 2015: Charting the Path to Sustainable Growth. IFPI, 2015.

IPSOS (Ipsos Connect) and IFPI (International Federation of the Phonographic Industry). Music Consumer Insight Report 2016. IPSOS and IFPI, 2016.

Jin, Dal Yong. New Korean Wave: Transnational Cultural Power in the Age of Social Media. U of Illinois P, 2016.

Jin, Dal Yong. "The Power of the National-State amid Neoliberal Reform: Shifting Cultural Politics in the New Korean Wave." Pacific Affairs, vol. 87, no. 1, 2014, pp. 71-92.

Jin, Dal Yong, and Woongjae Ryoo. "Critical Interpretation of Hybrid K-Pop: The GlobalLocal Paradigm of English Mixing in Lyrics." Popular Music and Society, vol. 37, no. 2, 2014, pp. 113-131.

Jung, So-Young. "Wŏlyopokŏsŭ, bluetek Ahn Tae-Ho taepyŏisa [Monday Focus, Bluetek's CEO, Ahn Tae-Ho]." Etnews, 25 Nov. 2001, http://www.etnews.com/200111230176. Accessed 25 Apr. 2018. 
Jung, Sun. "Fan Activism, Cybervigilantism, and Othering Mechanisms in K-pop Fandom." Transformative Works \& Cultures, vol. 10, 2012, http://dx.doi.org/10.3983/ twc.2012.0300.

Jung, Sun, and Doobo Shim. "Social Distribution: K-pop Fan Practices in Indonesia and the 'Gangnam Style' Phenomenon.” International Journal of Cultural Studies, vol. 17, no. 5, 2014, pp. 485-501.

Jung, Yuni. “isŏkch'ae KT hoechang 'aipon toip, chaebol i' [KT’s Chairman Lee 'Chaebols blocked introduction of the iPhone']." ZDNet Korea, 31 May 2012, http://www.zdnet. co.kr/news/news_view.asp?artice_id=20120531180931. Accessed 22 Apr. 2018.

Kay, John. "Why Sony Did Not Invent the iPod." JOHNKAY, 5 Sept. 2012, https:/www. johnkay.com/2012/o9/o5/why-sony-did-not-invent-the-ipod/. Accessed 25 Apr. 2018.

Kim, Byung-O. "A Study on the Process of Bootleg Records Popularization in Korea during 1960-8os." The Research of the Performance Art and Culture, vol. 24, 2012, pp. 47-78.

Kim, Jong-Hwa, and Jung-Hwan Lee. "Han'gukilbo 'aipon kisa' sakje nollan [Controversy: Hankook Ilbo Deleted 'iPhone Article']." Media Today, 6 Jan. 2010, http://www. mediatoday.co.kr/?mod=news\&act=articleView\&idxno=85260. Accessed 23 Apr. 2018.

Kim, Joo-Hyun. "Samsŏngchŏncha 'blutek' MP3 yŏnguchin hŭpsu [Samsung Took Back Bluetek's MP3 Research Team].” Kyunghyang Biz, 3 June 2005, http://biz.khan.co.kr/ khan_art_view.html?artid=200506031741411\&code=930201. Accessed 23 Apr. 2018.

Kim, Kwon-Yong. "LG, MP3pŏn ŭmakchŏchakkwon chimhaenollansok chulsiganghaeng [LG Releases Its MP3 Phone despite the Controversy over Copyright Infringement]." MBN, 10 Mar. 2004, http://news.mk.co.kr/newsRead.php?sc=30000oo1\&year=2004 $\&$ no $=73318$. Accessed 24 Apr. 2018.

Kim, Kyung-Geun. "Samsŏngchŏncha MP3saŏp chungbŏpin e nŏmgyŏ. Chahoesa 'blutek' sŏ insu [Samsung Handed over MP3 Section to Its Chinese Subsidiary, Bluetek]." The Korean Economic Daily, 14 Sept. 2001, http://news.hankyung.com/ article/2001091470871. Accessed 24 Apr. 2018.

Kim, Sang-Hoon. "aipon han'gukpanmae 1nyŏn ina gŏlin Kkadakŭn [Why did It Take One Year for the iPhone to Be Sold in Korea]." DongA, 19 Nov. 2009, http://news.donga. com/3/all/20091118/24203606/2. Accessed 23 Apr. 2018.

Kim, Se-Jin. "LGT.5 gae ŭmwondanch'e, MP3 pon punchaeng ch'oechong tagyŏl [LGT and Five Parties of the Korean Association of Phonogram Producers Finally Ended the MP3 Phone Conflict]." ZDNet Korea, 24 Nov. 2004, http://www.zdnet.co.kr/news/news_view. asp?artice_id=oooooo39131765. Accessed 25 Apr. 2018.

Lee, Hyo-Jung. "Samsŏng.LG chungsoteotbat 'yagŭmyagŭm' [Samsung and LG Penetrating Business Sectors for Small and Medium-Sized Companies]." MBN, 17 Sept. 2004, http:// news.mk.co.kr/newsRead.php?sc=30000001\&year=2004\&no=73102. Accessed 21 Apr. 2018.

Lee, Jung-Yup. "Managing the Transnational, Governing the National: Cultural Policy and the Politics of the 'Cultural Archetype Project' in South Korea." Popular Cultural and the States in East and Southeast Asia, Routledge, 2012, pp. 123-143.

Lee, Yong. "Chŏchakkwoncha ŭi kwonri nŭn pohodoeŏya handa [Intellectual Property Should Be Protected]." Chichŏk chaesankwon, vol. 3, 2004, pp. 137-138. 
Lee, Yong-Woo. "Migunkŭlŏpsŏ 'hullyŏnbadŭn" taechungŭmak [Korean Popular Music 'trained' in the US Army Clubs].' The Hankyoreh, 6 July 2005, http://www.hani.co.kr/ arti/culture/culture_general/47952.html. Accessed 18 Apr. 2018.

Leung, Lisa Yuk-Ming. "\#Unrequited Love in Cottage Industry? Managing K-pop (Transnational) Fandom in the Social Media Age." The Korean Wave, edited by Tae-Jin Yoon and Dal Yong Jin, Lexington Books, 2017, pp. 87-108.

Messerlin, Patrick, and Wonky Shin. "The K-pop Success: How Big and Why So Fast?" Asian Journal of Social Sciences, vol. 45, nos. 4-5, 2017, pp. 409-439.

Ministry of Trade, Industry and Energy. "Kawngbok 70 nyŏn, segye 6 ui such'uldaeguk 'uttuk' [Korea Reaches the Global Top 6 Exporting Countries, 70 Years after Its Liberation]." FTA Kangguk, Korea, 13 Aug. 2015, http://fta.go.kr/webmodule/htsboard/ template/read/fta_infoBoard_o4_view.jsp?typeID=8\&boardid=73\&seqno=14.1248. Accessed 18 Aug. 2018.

Mitchell, Allan. The Great Train Race: Railways and the Franco-German Rivalry, 1815-1914. Berghahn Books, 2000.

Moon, Hwy-Chang, Alan M. Rugman, and Alain Verbeke. "A Generalized Double Diamond Approach to the Global Competitiveness of Korea and Singapore." International Business Review, vol. 7, no. 2, 1998, pp. 135-150.

Oh, Byung-Il. "Iyongcha ŭi chŏngdanghan kwonri rŭl ch'imhaehaesŏnŭn andoenda [The Rights of Users should not be Infringed]." Chichŏk chaesankwon, vol. 3, 2004, pp. 139-140.

Oh, Ingyu. "The Globalization of K-pop: Korea's Place in the Global Music Industry." Korea Observer, vol. 40, no. 3, 2013, pp. 389-409.

Oh, Ingyu, and Gil-Sung Park. "From $\mathrm{B}_{2} \mathrm{C}$ to $\mathrm{B}_{2} \mathrm{~B}$ : Seeing Korean Pop Music in the Age of New Social Media." Korea Observer, vol. 43, no. 3, 2012, pp. 365-397.

Parc, Jimmyn, and Nobuko Kawashima. "Wrestling with or Embracing Digitization in the Music Industry: The Contrasting Business Strategies of J-pop and K-pop." Kritika Kultura, vol. 30/31, 2018, pp. 23-48.

Parc, Jimmyn, Patrick Messerlin, and Hwy-Chang Moon. "The Secret to the Success of K-pop: The Benefits of Well-balanced Copyrights." Corporate Espionage, Geopolitics, and Diplomacy Issues in International Business, edited by Bryan Christiansen and Fatmanur Kasarci, IGI Global, 2016, pp. 130-148.

Porter, Michael. The Competitive Advantage of Nations. The Free Press, 1990.

Rowinski, Dan. "4 Real Secrets We've Learned So Far About Apple." Readwriteweb.com, 8 Aug. 2012, https://readwrite.com/2012/08/07/4-real-secrets-weve-learned-so-farabout-apple/. Accessed 21 Apr. 2018.

Samsung. "Samsŏngchŏncha 45nyŏn, chepum hyŏksin ŭi yŏksa rŭl tolaboda 1pyŏn [Forty-Five Year History of Samsung, Retrospection on the History of Innovation Part 1]." Samsung Newsroom, 14 Apr. 2014, https://news.samsung.com/kr/삼성전자-45년제품-혁신의-역사를-돌아보다-1편-휴대. Accessed 23 Apr. 2018.

Shin, Kyung-Hee. "MP3 pŭleiŏ uihyŏphanŭn MP3 pon [MP3 Phone Intimidates MP3 Players]." Chŏngbohwa sahoe, vol. 175, 2005, pp. 20-21. 
Song, Jung-a. "Samsung Vows to Take Bite out of Apple." Financial Times, 30 Mar. 2005, https://www.ft.com/content/3e595e8a-aoa9-11d9-a3ba-oooooe2511c8. Accessed 24 Apr. 2018.

Titcomb, James. "What is Uber and Why Does TfL Want to Crack Down on It?" The Telegraph, 30 Sept. 2015, https://www.telegraph.co.uk/technology/uber/11902093/ What-is-Uber-and-why-does-TfL-want-to-crack-down-on-it.html. Accessed $27 \mathrm{Apr}$. 2018.

Van Buskirk, Eliot. "Bragging Rights to the World's First MP3 Player." CNET, 25 Jan. 2005, https://cnet.co/2nfAhpu. Accessed 4 May 2018.

Yang, Kimin. "Yurŏng chŏnchaeng-ŭmakchŏchakchadŭl kwa muryo MP3 saitŭ rŭl parabonŭn sisŏn [Ghost War: Song Writers and their View on Free of Charge MP3 Site]." Munhak kwa kyŏngkye, vol. 5, no. 4, 2005, pp. 228-239.

Yoo, Jin-Sang. "MP3 pŭleiŏ, 107\% sŏngchanghan 111 mandae, 1,86oŏkwon kyumo [MP3 Player, 107\% Growth with 1.1 Million Units and 186 Billion Won]." Computer World, 3 Aug. 2004, http://www.comworld.co.kr/news/articleView.html?idxno=92. Accessed 21 Apr. 2018.

Yoo, Seon-Sil. “Ŭmbanŏpgye wa MP3 sŏbisǔŏpch'e ganŭi kaldŭng kwa hyanghu chŏnmang [The Conflict between the Korean Music Industry and MP3 Music Providers and its Future Prospect]." Chŏngbo tongshin chŏngch'aek, vol. 12, no. 12, 200o, pp. 56-61. 